\title{
Strength, Jump Heights and Physical Characteristics of Young Male Basketball Players by Their Positions
}

\author{
Niyazi Sıdk1 Adıgüzel \\ Correspondence: Niyazi Sıdkı Adıgüzel, Presidency of the Republic of Turkey, Zip Code: 06560, Beştepe/Ankara, \\ Turkey.
}

Received: January 15, 2019

doi:10.11114/jets.v7i3S.4005

\author{
Accepted: January 29, 2019 Online Published: January 30, 2019 \\ URL: https://doi.org/10.11114/jets.v7i3S.4005
}

\begin{abstract}
The aim of the study is to compare isokinetic leg strengths and jump performances of basketball players playing at different positions. A total of 34 basketball players (guards $(n=13)$, forwards $(n=13)$ and centers $(n=7)$ ) from 17 teams of Turkish Basketball Development League participated in the study. The isokinetic strength tests were performed for the dominant limb at two different angular speeds $\left(60^{\circ} \mathrm{s}^{-1}\right.$ and $\left.180^{\circ} \mathrm{s}^{-1}\right)$ and the extensor and flexor peak torques (EPT and FPT) were recorded. The strengths produced according to weight were taken as relative EPT and FPT. Jump tests were performed in three categories: free jump, $120^{\circ}$ squat jump and active jump. Multivariate variance analysis (ANOVA) was used to compare players' scores in strength and jump tests by their positions. In the comparison of the positions, the guards were shorter and slimmer than the forwards and centers $(\mathrm{p}<0.05)$, and they were found to have less BMI values than the centers. The absolute strength values obtained with knee extension peak torques for both angular velocities were higher in the centers than the guards $(\mathrm{p}<0.05)$. There was no statistically significant difference in the relative strength values. Moreover, no statistically significant difference was found between the groups for other parameters and all jump parameters ( $p>0.05$ ). Consequently, it can be stated that there are physical differences among high-level young basketball players by their positions and absolute quadriceps strengths of the centers may be higher than of the guards.
\end{abstract}

Keywords: basketball, isokinetic strength, vertical jump, player's position

\section{Introduction}

The fact that each sports branch includes different performance demands may cause players to differ in physical characteristics. Many different studies have examined branch-specific physical and physiological differences in team sports so far, and as a result of these studies, some branch-specific physical profiles have been obtained (Gaurav \& Singh, 2010). For example, the advantages of height for basketball are not so much for football, so height is the main cause for significant differences in the physical profiles required by these two branches. In addition to branch-specific differences, it is known that players in the same sports branch will have different physical characteristics by their positions (Bloomfield, Polman, \& O'Donoghue, 2007). Previous studies have shown that players have different physical characteristics by their positions in basketball (Carter, Ackland, Kerr, \& Stapff, 2005). Players at the center position, who initiate the attempts underneath the basket most, are expected to be taller and heavier than guards, who set the game. In addition to physical characteristics, performance components such as strength, balance, jump and speed may vary by the positions in basketball (Delextrat \& Cohen, 2009) as well as in all other sports branches (Bale, 1991). There are studies revealing that there may be differences (Delextrat \& Cohen, 2009; Latin, Berg, \& Baechle, 1994) or no difference (Bale, 1991; Hoare, 2000; Ostojic, Mazic, \& Dikic, 2006) in the jump heights by the position of players in basketball. Although Delextrat and Cohen (2009) found no difference in two-leg vertical jump heights by the positions in their study on elite female basketball players, they discovered that single-leg jump heights of the guards are higher than of the centers and forwards. A similar case exists for the strength parameters. There are some studies showing that there may be differences or no difference in strength among the positions of basketball players (Abdelkrim, Chaouachi, Chamari, Chtara, \& Castagna, 2010). Although the physical differences of basketball players are partly apparent by their positions, the differences in performance components such as strength and force have not been clarified yet. It is thought that the contradictory findings in previous studies may be due to distinct research design populations. The physical profiles in basketball are characterized by many different factors such as age, gender, sports history as well as the positions of players (Hoare, 2000; Abdelkrim et al., 2010). In this context, this study population is homogeneous in 
terms of these three variables. The aim of this study is to examine both physical and strength and force differences of high-level young male basketball players.

\section{Materials and Methods}

34 basketball players without any chronic diseases from 17 teams of Turkish Basketball Development League participated in this study voluntarily. Age, height and body weight values of the players are as indicated in Table 1 . The ethics committee approval was obtained from Konya Selcuk University, Faculty of Sports Sciences, as well as the permission was taken from each player's guardians, team coaches, and club executives. The context and importance of the study were explained to the participants. In this study, two different performance tests, called isokinetic leg strength test and vertical jump test, were performed and all measurements were conducted in a laboratory in Ankara Gazi University, Faculty of Physical Education and Sports Sciences.

\subsection{Identifying Body Composition}

Heights of the participants were determined with the help of a stadiometer (SECA 707, Germany) with a precision of $0.01 \mathrm{~m}$ by measuring the distance between the vertebrae of head and foot following a deep inspiration. Body weights and bioimpedance analysis were determined in barefoot and shorts with the help of a weighing device (Tanita BC 418 MA MODEL) with a precision of 0.1 using a computer-assisted BIA method.

\subsection{Isokinetic Knee Strength Test}

Isokinetic knee strength tests were conducted by using an Isomed 2000 model dynamometer. Peak isokinetic concentric knee extension and knee flexion of all volunteers were measured at two motion angles for the dominant limb in a way of 5 repeats in 60 degrees per second angular velocity and 20 repeats in 180 degrees per second angular velocity. The tests were performed from low to high degrees (Perin, 1993). Voluntary individuals made five maximum extensions for each level. A 90-second passive resting break was given between each testing period (Newman, Tarpenning, Marino, 2004). During the test, the subjects were encouraged verbally. The best scores were recorded in N/m.

\subsection{Jump Tests}

Jump tests were conducted with Smartspeed Lite System brand jump mat and test equipment in three categories: free jump, $120^{\circ}$ squat jump and active jump. Each test was performed twice, and the best scores were recorded.

\section{Data Analysis}

The data obtained were analyzed with SPSS (Statistical Package for Social Sciences Inc. Chicago, IL, USA) "For Windows Release 21.0". In the analysis of the data, the data set was first examined in terms of erroneous value, outliers, and normality of the distribution. The normality was tested with the Shapiro-Wilk test and it was found that the distribution was normal $(p>0.05)$. The variables determined by the measurements were expressed as mean $(\mathrm{X})$ and standard deviation (S). Multivariate analysis of variance (ANOVA) was used to compare isokinetic leg strength and vertical jump test scores of the basketball players by their positions. $\mathrm{P}$ significance value was taken as $\mathrm{n}=0.05$ (Sümbüloğlu \& Sümbüloğlu, 1994).

\section{Results}

Since the center position is a more specific position, the number of samples for this position was less than that of other positions (Table 1). As expected, statistically significant differences were found between the groups in terms of physical characteristics.

Table 1. Physical characteristics

\begin{tabular}{lcccc}
\hline Positions & Guards $(\mathrm{n}=13)$ & Forwards $(\mathrm{n}=14)$ & Centers $(\mathrm{n}=7)$ & Total $(\mathrm{n}=34)$ \\
\hline Age & $15.61 \pm 0.77$ & $15.92 \pm 0.92$ & $16.57 \pm 0.53$ & $15.94 \pm 0.85$ \\
Height $(\mathrm{cm})$ & $181.62 \pm 6.23$ & $190.71 \pm 3.38^{*}$ & $195.43 \pm 4.96^{*}$ & $188.21 \pm 7.34$ \\
Weight $(\mathrm{kg})$ & $68.94 \pm 6.73$ & $78.82 \pm 7.79 *$ & $88.74 \pm 8.82^{*}$ & $77.09 \pm 10.53$ \\
BMI & $20.87 \pm 1.24$ & $21.68 \pm 2.17$ & $23.27 \pm 2.52^{*}$ & $21.69 \pm 2.09$ \\
\hline
\end{tabular}

Note. *Significant difference according to the ones at the guard position $(p<0.05)$. " Significant difference according to the ones at the forward position $(p<0.05)$.

Basketball players at the guard position were shorter and slimmer than the forwards and centers $(p<0.05)$. Again, it was observed that the guards had less BMI values than the centers. Although the difference in height between the centers and forwards was not statistically significant $(p>0.05)$, the centers were found to be heavier $(p<0.05)$.

It was reported that relative strength values will be more meaningful than absolute strength values in the context of the 
absolute effect of weight on strength (Iş̧1, Ünlü, Gözübüyük, Aslanyürek, \& Bereceli, 2018). Therefore, absolute strength values, as well as relative strength values, were considered as variables. The isokinetic strength tests were performed at two different angular velocities $\left(60^{\circ} \mathrm{s}^{-1}\right.$ and $\left.180^{\circ} \mathrm{s}^{-1}\right)$, and extensor and flexor peak torques (EPT and FPT) were recorded (Table 2 and 3). The strengths produced based on weight were considered as relative EPT and relative FPT.

Table 2. Knee extensor and flexor peak torques (EPT and FPT) for the dominant limb at $60^{\circ} \mathrm{s}^{-1}$

\begin{tabular}{lcccc}
\hline Positions & EPT & FPT & Relative EPT & Relative FPT \\
\hline Guards $(\mathrm{n}=13)$ & $222.75 \pm 34.12$ & $148.81 \pm 20.49$ & $3.23 \pm 0.36$ & $1.93 \pm 0.19$ \\
Forwards $(\mathrm{n}=14)$ & $232.48 \pm 27.75$ & $150.86 \pm 39.09$ & $2.97 \pm 0.39$ & $1.90 \pm 0.43$ \\
Centers $(\mathrm{n}=7)$ & $267.81 \pm 63.68^{*}$ & $131.40 \pm 24.16$ & $3.02 \pm 0.67$ & $1.83 \pm 0.36$ \\
Total $(\mathrm{n}=34)$ & $236.04 \pm 41.87$ & $146.07 \pm 30.32$ & $3.08 \pm 0.45$ & $1.90 \pm 0.57$ \\
\hline
\end{tabular}

Note. *Significant difference according to the ones at the guard position $(p<0.05)$.

While EPT values of the centers were higher than of the guards $(p<0.05)$ in the $60^{\circ} \mathrm{s}^{-1}$ angular isokinetic strength tests, no statistically significant difference was found between the groups for other parameters $(p>0.05)$.

Table 3. Knee extensor and flexor peak torques (EPT and FPT) for the dominant limb at $180^{\circ} \mathrm{s}^{-1}$

\begin{tabular}{lcccc}
\hline Positions & EPT & FPT & EPT $(\% \mathrm{BW})$ & FPT $(\% \mathrm{BW})$ \\
\hline Guards $(\mathrm{n}=13)$ & $192.38 \pm 26.11$ & $144.46 \pm 17.97$ & $2.81 \pm 0.40$ & $1.89 \pm 0.20$ \\
Forwards $(\mathrm{n}=14)$ & $207.28 \pm 24.83$ & $146.29 \pm 24.60$ & $2.65 \pm 0.36$ & $1.86 \pm 0.28$ \\
Centers $(\mathrm{n}=7)$ & $227.63 \pm 28.96^{*}$ & $132.86 \pm 17.65$ & $2.58 \pm 0.34$ & $1.87 \pm 0.40$ \\
Total $(\mathrm{n}=34)$ & $205.77 \pm 28.57$ & $142.83 \pm 20.97$ & $2.69 \pm 0.37$ & $1.87 \pm 0.27$
\end{tabular}

Note. *Significant difference according to the ones at the guard position $(p<0.05)$.

While EPT values of the centers were higher than of the guards $(p<0.05)$ in the $180^{\circ} \mathrm{s}^{-1}$ angular isokinetic strength tests, no statistically significant difference was found between the groups for other parameters $(p>0.05)$.

Absolute strength values obtained with knee extension peak torques for both angular velocities were higher in the centers than the guards $(p<0.05)$. There was no statistically significant difference in relative strength values.

Three different procedures were followed to measure the jump height, which is another performance component (Table 4).

Table 4. Jump Heights

\begin{tabular}{lcccc}
\hline Positions & Guards $(\mathrm{n}=13)$ & Forwards $(\mathrm{n}=14)$ & Centers $(\mathrm{n}=7)$ & Total $(\mathrm{n}=34)$ \\
\hline Free Jump $(\mathrm{cm})$ & $41.38 \pm 3.33$ & $37.13 \pm 5.19$ & $36.81 \pm 11.82$ & $38.69 \pm 6.68$ \\
Squat Jump & $33.69 \pm 3.69$ & $30.17 \pm 5.07$ & $29.24 \pm 6.55$ & $31.33 \pm 5.15$ \\
Active Jump & $35.10 \pm 3.16$ & $32.47 \pm 3.89$ & $31.83 \pm 8.45$ & $33.35 \pm 4.96$ \\
\hline
\end{tabular}

No statistically significant difference was found between the groups for all jump parameters and all three jump tests $(p>0.05)$.

\section{Discussion}

It is known that basketball players have different physical characteristics by their positions. Moreover, it was previously reported that there may also be differences in performance components (Abdelkrim et al., 2010). One of the reasons for the differences in physical characteristics of basketball players is thought to be positioning them by their coaches according to their physical characteristics. Another reason is that the condition and physical characteristics of a player change regarding the position-specific physical performance demands. It was previously revealed that basketball players may have different acute physiological post-competition responses by their positions (Rodriguez-Alonso, Fernandez-Garcia, Perez-Landaluce, \& Terrados, 2003). In line with these demands, while performance components such as strength, force and durability are expected to have differences, previous studies reported contradictory findings. The fact that previous studies were conducted with different research design populations makes it difficult to draw common conclusions from these studies. At this point, significant results may be obtained by generating a homogeneous population in terms of the variables age, gender and sportive readiness. This study examined the physical differences of 
high-level basketball players in the youth category by their positions, as well as the differences in strength and jump. In terms of physical differences, the main finding in the present study is that the guards are slimmer and shorter than both centers and forwards, which is similar to previous studies (Jeličić, Sekulić, \& Marinović, 2002). In their study, which is one of the earliest studies examining the physical differences of basketball players by their positions, Latin et al., (1994) reported that the guards are much shorter than both the forwards and centers. Abdelkrim et al. (2010) have recently revealed that the centers and power forwards are taller and heavier than the guards.

Considering the variable strength, it was observed that the centers have higher extensor strength values than the guards. However, these differences are not significant for relative values. Absolute maximal strength of quadriceps muscles is higher in the centers. In addition, flexor strength values did not differ by the positions. Maximal strength of the hamstring muscle, which helps knee in flexion, may not be different by the position. In their study, Delextrat and Cohen (2009) compared relative strengths of female basketball players by the positions and found relative strengths of the forwards are more than the centers at the $60^{\circ} \mathrm{s}^{-1}$ and $180^{\circ} \mathrm{s}^{-1}$ angular velocities. They found no statistically significant difference in absolute strength values by the positions. Although there are other studies demonstrating that players at the guard position are better at relative strength (Latin et al., 1994), no statistically significant difference was found in these studies. However, this study revealed that the guards produce similar absolute strengths although they are slimmer since there is no statistical difference between absolute strengths and the positions for the hamstring region, and the centers and forwards are heavier than the guards. This can be counted as informative data that will feature the guards in relative strength. The reason why the differences are not statistically significant is thought that excess weight of the centers is not due to the muscle mass but excess fat. It is known that strength is related to lean body weight rather than total body weight (Iş̧1k et al., 2018). Parallel to this, it is known that basketball players who play at the center position may have more fat percentage due to some advantages to be provided by it for physical contacts (setting screen against the opponent to penetrate the guards, battles underneath the basket) (Ostojic et al., 2006). It is a common opinion in the literature that absolute strength of the centers will be higher than the basketball players at other positions (Abdelkrim et al., 2010).

In this study, it was discovered that the jump heights of the young basketball players were not different by their positions. In his study, Bale (1991) reported that there may be a similarity in vertical jumps by the positions in basketball. Ostojic et al. (2006) reported that vertical jump heights do not differ by the positions, but relative values show that the guards have higher values than the centers. Abdelkrim et al. (2010) showed that the centers have less vertical jump height than the guards and forwards. Since different jump techniques were used in above-mentioned studies, it may not be appropriate to compare these studies with each other. 3 different jump techniques were used to bring the elements, such as hand positions (free or on waist), ground contact times, joint motion width, under control (Deliceoğlu et al., 2017), which could affect the jump heights. However, it was observed that the differences between the groups were not statistically significant in all jump procedures.

Although there are studies in which players' positions in basketball were discussed for five different positions (Harris, Stone, O’bryant, Proulx, \& Johnson, 2000; Dežman, Trninić, \& Dizdar, 2001), such classifications impose a limitation for the players playing in more than one position. It may not be possible to find a single major position for the ones who can play at two or more positions. In addition, the fact that basketball players who play at the $1^{\text {st }}$ and $2^{\text {nd }}$ positions can be assigned in similar formats, as well as the fact that the players who play at $3^{\text {rd }}$ and $4^{\text {th }}$ positions can often take part in each other's places suggest that it may not be the right way to consider them in different groups. Based on this information, our study did not consider the players' positions as 5 different positions in basketball but made a comparison by clustering similar positions in a single group. There are also studies that made such a grouping similar to our study (Abdelkrim et al., 2010; Delextrat \& Cohen, 2009).

\section{Conclusion}

This study suggested that there were physical differences among high-level young basketball players by their positions. The forwards and centers are taller and heavier than the guards. In addition, the jump heights are not different by the positions. It can be stated that absolute quadriceps strengths of the centers may be more than the guards. However, hamstring strengths are similar.

\section{References}

Abdelkrim, N. Ben, Chaouachi, A., Chamari, K., Chtara, M., \& Castagna, C. (2010). Positional role and competitive-level differences in elite-level men's basketball players. The Journal of Strength \& Conditioning Research, 24(5), 1346-1355. http://doi.org/10.1519/JSC.0b013e3181cf7510

Bale, P. (1991). Anthropometric, body composition and performance variables of young elite female basketball players. The Journal of Sports Medicine and Physical Fitness, 31(2), 173-177. 
Bloomfield, J., Polman, R., \& O'Donoghue, P. (2007). Physical demands of different positions in FA Premier League soccer. Journal of Sports Science \& Medicine, 6(1), 63.

Carter, J. E. L., Ackland, T. R., Kerr, D. A., \& Stapff, A. B. (2005). Somatotype and size of elite female basketball players. Journal of Sports Sciences, 23(10), 1057-1063. https://doi.org/10.1080/02640410400023233

Delextrat, A., \& Cohen, D. (2009). Strength, power, speed, and agility of women basketball players according to playing position. The Journal of Strength \& Conditioning Research, 23(7), 1974-1981. https://doi.org/10.1519/JSC.0b013e3181b86a7e

Deliceoğlu, G., Ünlü, G., Coşkun, B., Tortu, E., Kocahan, T., \& Koçak, S. (2017). The Effect Of Ground Contact Time And Drop Height On Work And Power Outputs For Drop Jump In Youth Turkish National Volleyball Players. Journal of Physical Education \& Sports Science/Beden Egitimi ve Spor Bilimleri Dergisi, 11(3).

Dežman, B., Trninić, S., \& Dizdar, D. (2001). Expert model of decision-making system for efficient orientation of basketball players to positions and roles in the game-Empirical verification. Collegium Antropologicum, 25(1), $141-152$.

Gaurav, V., \& Singh, S. (2010). Anthropometric characteristics, somatotyping and body composition of volleyball and basketball players. Journal of Physical Education and Sport Management, 1(3), 28-32. https://doi.org/10.5897/JPESM

Harris, G. R., Stone, M. H., O’bryant, H. S., Proulx, C. M., \& Johnson, R. L. (2000). Short-term performance effects of high power, high force, or combined weight-training methods. The Journal of Strength \& Conditioning Research, 14(1), 14-20.

Hoare, D. G. (2000). Predicting success in junior elite basketball players-the contribution of anthropometic and physiological attributes. Journal of Science and Medicine in Sport, 3(4), 391-405. https://doi.org/10.1016/S1440-2440(00)80006-7

Isık, A., Unlu, G., Gozubuyuk, O. B., Aslanyurek, T., \& Bereceli, C. (2018). The relationship between previous lower extremity injury, body weight and bilateral eccentric hamstring strength imbalance in young soccer players. Montenegrin Journal of Sports Science and Medicine, 7(2). https://doi.org/10.26773/mjssm.180904

Jeličić, M., Sekulić, D., \& Marinović, M. (2002). Anthropometric characteristics of high level European junior basketball players. Coll. Antropol, 26, 69-76.

Latin, R. W., Berg, K., \& Baechle, T. (1994). Physical and performance characteristics of NCAA division I male basketball players. The Journal of Strength \& Conditioning Research, 8(4), 214-218.

Newman, M. A., Tarpenning, K. M., Marino, F. E. (2004). Relationship between isokinetic knee strength, single-sprint performance, and repeated-sprint agility in football players. Journal of Strength and Conditioning Research, 18(4), 867-872. https://doi.org/10.1519/13843.1

Ostojic, S. M., Mazic, S., \& Dikic, N. (2006). Profiling in basketball: Physical and physiological characteristics of elite $\begin{array}{llllll}\text { players. Journal of Strength and Conditioning Research, 20(4), } 740 . & .\end{array}$ https://doi.org/10.1519/00124278-200611000-00003

Perin, D. H. (1993). Exercise and Isokinetic Assessment. 2nd ed. Champaign IL: Human Kinetics Boks, 25-31

Rodriguez-Alonso, M., Fernandez-Garcia, B., Perez-Landaluce, J., \& Terrados, N. (2003). Blood lactate and heart rate during national and international women's basketball. Journal of Sports Medicine and Physical Fitness, 43(4), 432.

Sümbüloğlu, K., Sümbüloğlu, V. (1994). Biyoistatistik. Ankara: Özdemir Yayınc1lı.

\section{Copyrights}

Copyright for this article is retained by the author(s), with first publication rights granted to the journal.

This is an open-access article distributed under the terms and conditions of the Creative Commons Attribution license which permits unrestricted use, distribution, and reproduction in any medium, provided the original work is properly cited. 